\title{
Fluorinated Polymethacrylates as Highly Sensitive Non-chemically Amplified e-beam Resists
}

\author{
Jeffrey R. Strahan ${ }^{\mathrm{a}}$, Jacob R. Adams ${ }^{\mathrm{a}, \mathrm{b}}$, Wei-Lun Jen ${ }^{\mathrm{a}}$, Anja Vanleenhove ${ }^{\mathrm{c}}$, Colin C. Neikirk ${ }^{\mathrm{a}}$, \\ Timothy Rochelle ${ }^{\mathrm{a}}$, Roel Groneid ${ }^{\mathrm{b}}$, C. Grant Willson*a \\ ${ }^{a}$ The University of Texas at Austin, Department of Chemistry, 1 University Station A5300, Austin, \\ TX, USA 78712; \\ ${ }^{\mathrm{b}}$ IMEC vwz, Kapeldreef 75, Leuven 3001, Belgium; \\ ${ }^{c}$ NXP Semiconductors, Kapeldreef 75, Leuven 3001, Belgium
}

\begin{abstract}
In an effort to improve upon the sensitivity of commercial non-chemically amplified e-beam resists, four polyacrylates functionalized with $\alpha-\mathrm{CF}_{3}$ and/or $\mathrm{CH}_{2} \mathrm{CF}_{3}$ alkoxy substituents were studied. The $\alpha-\mathrm{CF}_{3}$ substituent is known to increase backbone-scission efficiency while simultaneously eliminating acidic out-gassing and cross-linking known to occur in $\alpha$ halogen substituted polyacrylates. Contrast curves for the polymeric $\alpha-\mathrm{CF}_{3}$ acrylates, generated through e-beam exposure, showed the resists required an order of magnitude less dose than the current industry-standards, PMMA and ZEP. The fundamental sensitivity of these materials to backbone scissioning was determined via ${ }^{60} \mathrm{Co} \gamma$-ray irradiation. The chain scissioning, $\mathrm{G}(\mathrm{s})$, and cross-linking, $\mathrm{G}(\mathrm{x})$, values calculated from the resulting change in molecular weight demonstrated that all fluorinated resists possess higher G(s) values than either PMMA or ZEP and have no detectable $\mathrm{G}(\mathrm{x})$ values. Utilizing e-beam and EUV interference lithographies, the photospeed of PMTFMA was found to be $2.8 \mathrm{x}$ and 4.0x faster, respectively, than PMMA.
\end{abstract}

Keywords: e-beam, PMMA, ZEP, G(s), G(x), and EUV

*willson@che.utexas.edu, phone 1512471 3975, fax 1512471 7222, willson.cm.utexas.edu/

\section{INTRODUCTION}

Electron-beam lithography (EBL) has been and continues to be a major component of the semiconductor manufacturing process. A gate-level mask requires approximately twenty-four hours to write using a state-of-the-art, fifteen to twentyfive million dollar variable beam shape e-beam exposure tool. A fully functioning mask set for 65 or $45 \mathrm{~nm}$ production can total one to two million dollars and requires forty to fifty masks with many rewrites. Therefore, a decrease in write time will lead to more efficient production of mask sets. ${ }^{1}$,

While mask writing is the most prominent use of EBL, new 'maskless' technologies have emerged in recent years that take advantage of its resolution capabilities. In 2008, Slot et al. reported the use of 13,000 simultaneous electron beams controlled by an electrostatic lens array to produce sub-45 $\mathrm{nm}$ lines and spaces. ${ }^{3}$ This technology could make a significant contribution in the industry and lead to actual semiconductor devices, not just masks, being produced by EBL. In the same year, Samsung Electronics reported the fabrication of $40 \mathrm{~nm}$ lines and spaces with line width roughness $(3 \mathrm{~s}=3.7 \mathrm{~nm}) .{ }^{4}$ Resolution on this order is needed to produce templates for nano-imprint lithography. If EBL is to expand to full-scale production for these technologies, throughput must increase. Improvements in resist sensitivity could lead to shorter exposure times per wafer and thus, higher throughput.

PMMA has long been the workhorse resist for gate-level e-beam mask writing because its etch resistance and resolution are acceptable for current processing requirements. ${ }^{5,6}$ However because the system is not chemically amplified, the exposure time for a 65 or $45 \mathrm{~nm}$ reticle is on the order of one day, as mentioned above. ZEP, a copolymer of methyl $\alpha$ chloroacrylate and $\alpha$-methyl styrene produced by Nippon Zeon Company, is a non-chemically amplified e-beam resist. ${ }^{7}$ It provides the high resolution needed to write small features using EBL and is more sensitive to backbone scission than PMMA due to the $\alpha$-chloro substituent. Extensive work by Pittman demonstrated that $\alpha$-halogen, electron-withdrawing

Advances in Resist Materials and Processing Technology XXVI, edited by Clifford L. Henderson, Proc. of SPIE Vol. 7273, 72733G · ( ) 2009 SPIE - CCC code: 0277-786X/09/\$18 · doi: 10.1117/12.813736 
substituents increase the backbone-scission efficiency. However, this substituent also undergoes dissociative-electron capture leading to the undesirable evolution of $\mathrm{HCl}$ and cross-linking within the resist. ${ }^{8}$

Willson and Ito first introduced the concept of utilizing an $\alpha-\mathrm{CF}_{3}$ substituent in resists for EBL. ${ }^{9}$ They proposed the $\alpha$ $\mathrm{CF}_{3}$ should preclude dissociative-electron capture and cross-linking but due to it's electron-withdrawing character still enhance the main-chain scission efficiency, thereby reducing the time required for imaging. Desiring to continue this work, methyl trifluoromethacrylate $\mathbf{1}$ was produced via two synthetic pathways and polymerized as both a homopolymer (P1) and a copolymer with MMA and styrene. In addition, ethyl trifluoromethacrylate, 2,2,2-trifluoroethyl methacrylate, and 2,2,2-trifluoroethyl trifluoromethacrylate were obtained as generous gifts from Central Glass Co. and polymerized (P2, P3, P4, respectively). PMMA (P5) was also synthesized via atom transfer radical polymerization (ATRP) as a point of reference for all imaging experiments. These polymers were compared to determine the effects of an $\alpha-\mathrm{CF}_{3}$ and/or $\mathrm{CH}_{2} \mathrm{CF}_{3}$ alkoxy substituent on a polyacrylate (Scheme 1).

A

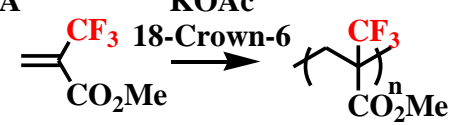

1

P1
B

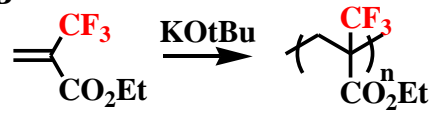

P2

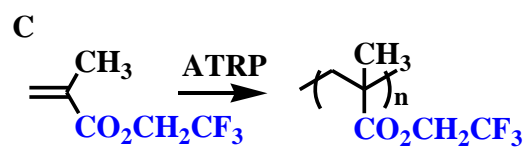

P3

D

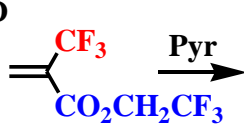

$\mathbf{E}$

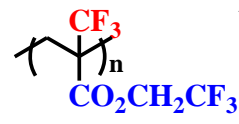

P4

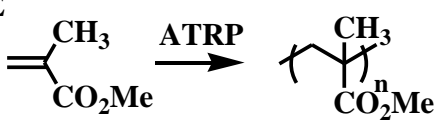

P5

Scheme 1: Polymerization conditions for A) Poly(methyl $\alpha$-trifluoromethacrylate (P1) B) Poly(ethyl $\alpha$ trifluoromethacrylate) (P2) C) Poly(2,2,2-trifluoroethyl methacrylate) (P3) D) Poly(2,2,2-trifluoroethyl $\alpha$ trifluoromethacrylate) (P4) E) Poly(methyl methacrylate) (P5)

To investigate the sensitivity of these materials as non-chemically amplified e-beam resists, contrast curves were generated for the polymeric $\alpha-\mathrm{CF}_{3}$ acrylates, and a selection of these polymers was exposed to ${ }^{60} \mathrm{Co}$ radiation to determine their G-values. Utilizing modeling data from Smith that shows increased fluorine content increases the absorbance of polyacrylates to Extreme Ultra Violet (EUV) irradiation $(13.4 \mathrm{~nm}){ }^{10}$ the sensitivity of $\mathbf{P 5}$ and P1 was compared using EUV interference lithography.

\section{METHODOLOGY}

\subsection{General Methods and Materials}

All chemicals were purchased from Sigma-Aldrich and used as received unless otherwise stated. ZEP-520 was purchased from Nippon Zeon Co. After precipitating in $0{ }^{\circ} \mathrm{C} \mathrm{MeOH}$, the polymer was isolated by filtration and dried in vacuo. AP410 was purchased from Silicon Resources, Inc. All reactions were conducted under a positive nitrogen atmosphere with oven-dried glassware unless otherwise stated. Dry DCM, TEA, and pyridine were obtained by distillation over $\mathrm{CaH}_{2}$ while dry THF was obtained by distillation over $\mathrm{Na} /$ benzophenone. All ${ }^{1} \mathrm{H}$ and ${ }^{13} \mathrm{C}$ NMR spectra were recorded on a Varian Unity Plus $300 \mathrm{MHz}$ instrument. All chemical shifts are reported in ppm downfield from TMS using the residual protonated solvent as an internal standard $\left(\mathrm{CDCl}_{3},{ }^{1} \mathrm{H} 7.26 \mathrm{ppm}\right.$ and ${ }^{13} \mathrm{C} 77.0 \mathrm{ppm}$; DMSO- $\mathrm{d}_{6},{ }^{1} \mathrm{H}$ $2.49 \mathrm{ppm}$ and ${ }^{13} \mathrm{C} 39.5 \mathrm{ppm}$ ). HRMS (CI) was obtained on a VG analytical ZAB2-E instrument. IR data was recorded on a Nicolet Avatar 360 FT-IR and all peaks are reported in $\mathrm{cm}^{-1}$. All molecular weights were measured using an Agilent 1100 Series Isopump and Autosampler, and a Viscotek Model 302 TETRA Detector Platform with 3 I-series Mixed Bed High MW columns. Films were spin coated and baked on a Brewer CEE 100CB Spincoater \& Hotplate. A $50 \mathrm{keV}$ JEOL-6000FS/E-based e-beam tool was used for exposures, and a Veeco Dektak 6M Stylus Profiler was used to determine film thicknesses.

\subsection{Monomer Synthesis}

Trifluoracetone cyanohydrin, $\mathbf{3}$ 
A $500 \mathrm{~mL}$ round bottom flask (RBF) equipped with a stir bar was charged with sodium cyanide (65.5 g, 1.3 mol) and $\mathrm{H}_{2} \mathrm{O}(190 \mathrm{~mL})$. After cooling the reaction flask in an ice-water bath, $2(13 \mathrm{~mL}, 0.14 \mathrm{~mol})$ was added. The reaction was stirred for $1 \mathrm{~h}$ and then added to $700 \mathrm{~mL}$ of $6 \mathrm{M}$ sulfuric acid and stirred for an additional hour. Addition to the acid resulted in release of cyanide gas; hence this reaction should be carried out in a well tested fume hood.. The reaction mixture was extracted with ether $(3 \times 200 \mathrm{~mL})$ and the combined organic layers were washed with a saturated aqueous solution of sodium bicarbonate, rinsed with brine, dried over $\mathrm{MgSO}_{4}$, filtered, and concentrated in vacuo. Vacuum distillation $\left(35\right.$ torr, $\left.49-55^{\circ} \mathrm{C}\right)$ yielded 3 as a clear liquid $(11.46 \mathrm{~g}, 60 \%) .{ }^{1} \mathrm{H}$ NMR $\left(\mathrm{CDCl}_{3}\right) \delta 4.52(\mathrm{~s}, 1 \mathrm{H}), 1.76(\mathrm{~s}, 3 \mathrm{H})$; ${ }^{13} \mathrm{C} \mathrm{NMR}\left(\mathrm{CDCl}_{3}\right) \delta 20.87$ (s), 69.29 (q) 115.77 (s), 122.17 (q); ${ }^{19} \mathrm{~F}$ NMR $\left(\mathrm{CDCl}_{3}\right) \delta-82.43 ; \mathrm{IR}(\mathrm{NaCl}) 3400,1706$; HRMS (CI) M+1 calc $=140.0323$, found 140.0326 .

Methyl $\alpha$-hydroxy- $\alpha$-(trifluoromethyl) propionate, 4

A $500 \mathrm{~mL}$ RBF equipped with a stirbar and condenser was charged with conc. $\mathrm{H}_{2} \mathrm{SO}_{4}(60 \mathrm{~mL}, 1.1 \mathrm{~mol})$. In a separate flask, 3 (90.1 g, $0.65 \mathrm{~mol}$ ) was mixed with $\mathrm{MeOH}(54 \mathrm{~mL})$, and the mixture was slowly added by syringe to the acid. After drop-wise addition of $\mathrm{H}_{2} \mathrm{O}(11.7 \mathrm{~mL}, 0.65 \mathrm{~mol})$, the reaction mixture was heated at $105{ }^{\circ} \mathrm{C}$ for $8.5 \mathrm{~h}$ then cooled to $80^{\circ} \mathrm{C}$ for another $13.75 \mathrm{~h}$. Upon cooling to rt, $\mathrm{H}_{2} \mathrm{O}(20 \mathrm{~mL})$ was added to the mixture. The crude mixture was extracted with ether $(3 \times 250 \mathrm{~mL})$ and the combined organic layers were washed with water, brine, dried over $\mathrm{MgSO}_{4}$, filtered, and concentrated in vacuo. Vacuum distillation $\left(55\right.$ torr, $\left.55-58^{\circ} \mathrm{C}\right)$ yielded 3 as a clear liquid $(53.63 \mathrm{~g}, 48 \%) .{ }^{1} \mathrm{H}$ NMR $\left(\mathrm{CDCl}_{3}\right) \delta 1.69(\mathrm{~s}, 3 \mathrm{H}) 1.86(\mathrm{~s}, 3 \mathrm{H}) 8.37(\mathrm{~s}, 1 \mathrm{H}) ;{ }^{13} \mathrm{C} \mathrm{NMR}\left(\mathrm{CDCl}_{3}\right) \delta 18.79(\mathrm{~s}), 54.02(\mathrm{~s}), 75.37(\mathrm{q}), 123.55(\mathrm{q}), 170.77(\mathrm{~s}) ;$ ${ }^{19} \mathrm{~F} \mathrm{NMR}\left(\mathrm{CDCl}_{3}\right) \delta-80.731 ; \mathrm{IR}(\mathrm{NaCl}) 3492,3013,2964,1741 ; \mathrm{HRMS}(\mathrm{CI}) \mathrm{M}+1 \mathrm{calc}=173.0426$, found 173.0433.

Methyl $\alpha$-acetoxy- $\alpha$-(trifluoromethyl) propionate, 5

A $500 \mathrm{~mL}$ RBF equipped with a stir bar and condenser was charged with $4(53.6 \mathrm{~g}, 0.31 \mathrm{~mol})$, acetic anhydride $(92 \mathrm{~mL}$, $0.97 \mathrm{~mol})$, and sodium acetate $(4.6 \mathrm{~g}, 56 \mathrm{mmol})$. This was heated to $110^{\circ} \mathrm{C}$ and stirred for $8 \mathrm{~h}$. After cooling to rt, the reaction mixture was added to ice $(700 \mathrm{~g})$ and stirred for $1 \mathrm{~h}$. The crude mixture was extracted with ether $(3 \times 200 \mathrm{~mL})$ and the combined organic layers were washed with $200 \mathrm{~mL}$ portions of saturated sodium bicarbonate solution until neutral. The organic layers were washed with brine $(200 \mathrm{~mL})$, dried over $\mathrm{MgSO}_{4}$, and concentrated in vacuo. Vacuum distillation $\left(60\right.$ torr, $\left.90-95^{\circ} \mathrm{C}\right)$ yielded 5 as a clear liquid $(85.4 \mathrm{~g}, 92 \%) .{ }^{1} \mathrm{H}$ NMR $\left(\mathrm{CDCl}_{3}\right) \delta 1.79(\mathrm{~s}, 3 \mathrm{H}), 2.13(\mathrm{~s}, 3 \mathrm{H})$, $3.79(\mathrm{~s}, 3 \mathrm{H}) ;{ }^{13} \mathrm{C} \mathrm{NMR}\left(\mathrm{CDCl}_{3}\right) \delta 16.47(\mathrm{~s}), 20.60(\mathrm{~s}), 53.389(\mathrm{~s}), 79.30(\mathrm{q}), 120.73(\mathrm{~s}), 165.50(\mathrm{~s}), 168.60(\mathrm{~s}) ;{ }^{19} \mathrm{~F}$ NMR $\left(\mathrm{CDCl}_{3}\right) \delta$-79.10; IR (NaCl) 3502, 3015, 2962, 1829, 1772, 1717; HRMS (CI) M+1 calc = 215.0531, found 215.0528.

\section{Methyl 2-trifluoromethacrylate, 1}

A quartz pyrolysis column (42 cm (heated length) with $4 \mathrm{~cm}$ outer diameter (OD)) packed with 20 feet of $5 \mathrm{~mm}$ OD, 3 $\mathrm{mm}$ inner diameter (ID) quartz tubing and 44 feet of $3 \mathrm{~mm}$ OD, $1 \mathrm{~mm}$ ID quartz tubing cut into lengths of $0.5 \mathrm{~cm}$ to 1 $\mathrm{cm}$. and wrapped with heating tape (HTS/Amptek Co Model AWH-051-0600) was used. Two temperature probes were positioned about $1 / 3$ of the column from the top and bottom respectively. These probes were secured with the tips directly between the heating tape and the column. The column was wrapped with two layers of insulation tape (Wale Apparatus Co. 151508) and aluminum foil. An addition funnel was added to the top of the column, and a cold finger and collection flask were attached at the bottom. The column was brought to $500{ }^{\circ} \mathrm{C}$ under nitrogen, and $5(79.7 \mathrm{~g}, 0.37 \mathrm{~mol})$ was introduced at approximately four drops per second. Nitrogen was flowed through the system at four bubbles per second, regulated by a needle valve at the beginning of the system and a bubbler at the end. Product $\mathbf{5}$ was added over 35 min while paying careful attention to minimize the build up of any smoke at the top of the column. Immediately after the last drop of $\mathbf{5}$ was added, the addition funnel was shut. The heat and nitrogen were continued to ensure a complete reaction. The collected product was washed three times with brine $(200 \mathrm{~mL})$ and dried over $\mathrm{MgSO}_{4}$. This was distilled from the drying agent to give 1 as a clear liquid. The first fraction (14.3 g, 25.0\%) was collected with a 9" vigreaux column wrapped with cotton and aluminum foil at atmospheric pressure from $83-87^{\circ} \mathrm{C}$. A second fraction $(12.1 \mathrm{~g}$, $21.0 \%$ ) was collected with a 3 " vigreaux column at 60 torr and $103-107^{\circ} \mathrm{C} .{ }^{1} \mathrm{H}$ NMR $\left(\mathrm{CDCl}_{3}\right) \delta 3.80(\mathrm{~s}, 3 \mathrm{H}), 6.60(\mathrm{~s}$, $1 \mathrm{H}), 6.68(\mathrm{~s}, 1 \mathrm{H}) ;{ }^{13} \mathrm{C} \mathrm{NMR}\left(\mathrm{CDCl}_{3}\right) \delta 52.44(\mathrm{~s}), 121.22(\mathrm{q}, J=270.4 \mathrm{~Hz}), 132.85(\mathrm{~s}), 161.72(\mathrm{~s}) ;{ }^{19} \mathrm{~F} \mathrm{NMR}\left(\mathrm{CDCl}_{3}\right) \delta-$ 66.47; IR ( NaCl) 3136, 3014, 2962; HRMS (CI) M+1 calc = 155.0318, found 155.0320.

Alternatively, 2-(trifluoromethyl)acrylic acid, $\mathbf{6}^{11}(75 \mathrm{~g}, 0.54 \mathrm{~mol})$ was dissolved in dimethylsulfate $(500 \mathrm{~mL})$ and the reaction vessel was heated to $120^{\circ} \mathrm{C}$ under an atmosphere of nitrogen for $48 \mathrm{~h}$. The color of the reaction changed to dark brown over $6 \mathrm{~h}$. After the reaction was cooled to rt, the crude reaction was subjected to vacuum distillation by heating the still pot to $120^{\circ} \mathrm{C}$ and cooling the receiving flask with dry ice $\left(-78{ }^{\circ} \mathrm{C}\right)$. The pressure was gradually reduced to 100 millitorr over $1 \mathrm{~h}$, maintaining the temperature of the still head at $\sim 100{ }^{\circ} \mathrm{C}$ to obtain $60 \mathrm{~g}(73 \%)$ of clear liquid. The ${ }^{1} \mathrm{H}$ 
NMR analysis of the liquid indicated the material collected consisted of desired product 1 with approximately 6 mol\% of dimethyl sulfate impurity. Second distillation with a vigreaux column was performed at atmospheric pressure and a fraction boiling at $75-80^{\circ} \mathrm{C}$ was collected to obtain the desired product $(45 \mathrm{~g}, 55 \%)$ with no detectable impurities.

\subsection{Polymer Synthesis}

Poly(methyl $\alpha$-trifluoromethacrylate), P1

A $50 \mathrm{~mL}$ RBF equipped with a stirbar was charged with oven-dried potassium acetate $(23.6 \mathrm{mg}, 0.28 \mathrm{mmol})$ and 18 crown-6 (63.4 mg, $0.24 \mathrm{mmol})$. These were dissolved in THF $(20 \mathrm{~mL})$ and cooled to $-5^{\circ} \mathrm{C}$ in an ice/brine bath. Upon addition of $1(5 \mathrm{~mL}, 39.0 \mathrm{mmol})$, the reaction was stirred for $3 \mathrm{~h}$. To precipitate the polymer, the reaction solution was slowly dripped into $500 \mathrm{~mL}$ of ice-cold vigorously stirring $\mathrm{MeOH}$ in an Erlenmeyer flask. The polymer was isolated using a Hirsch funnel and filter paper. The polymer was then dissolved in THF $(50 \mathrm{~mL})$ and precipitated again as described above using roughly ten times the volume of $\mathrm{MeOH}$ as THF. This procedure gave excellent yields (5.48 g, 91 $\%)$ of a fine white powder.

Poly(ethyl $\alpha$-trifluoromethacrylate), $\mathbf{P 2}$

A $25 \mathrm{~mL}$ RBF equipped with a stirbar was charged with potassium tert-butoxide $(6.7 \mathrm{mg}, 0.06 \mathrm{mmol})$ in a glove box. After removing the flask from the glove box, THF $(5 \mathrm{~mL})$ was added to the flask. The flask was then chilled to $-78^{\circ} \mathrm{C}$ with an acetone/dry ice bath, and ethyl $\alpha$-trifluoromethacrylate $(0.5 \mathrm{~mL}, 3.6 \mathrm{mmol})$ was added. The reaction flask was stirred and warmed to $\mathrm{rt}$ overnight, and $\mathbf{P 2}$ was precipitated using the same procedure as P1 precipitation but using hexanes instead of $\mathrm{MeOH}$.

Poly(2,2,2-trifluoroethyl methacrylate), $\mathbf{P 3}$

A $10 \mathrm{~mL}$ RBF equipped with a stirbar was loaded with $\mathrm{Cu}(\mathrm{I}) \mathrm{Br}(20.65 \mathrm{mg}, 0.144 \mathrm{mmol})$ in a glove box. After removing the flask from the glove box, trifluoroethyl methacrylate $(2 \mathrm{~mL}, 14.0 \mathrm{mmol})$ was added. After hexamethyltriethylenetetramine (TREN) $(31.969 \mu \mathrm{l}, 0.144 \mathrm{mmol})$ and E2BIB $(17.79 \mu \mathrm{l}, 0.12$ moles) were added via micro syringe, the flask was taken through two freeze, pump, thaw cycles and then heated to $80{ }^{\circ} \mathrm{C}$ for $4.5 \mathrm{~h}$. The reaction solution formed a gelatinous solid, so it was dissolved in THF for removal. The polymer was precipitated in $\mathrm{MeOH}$ as described for $\mathbf{P 1}$.

Poly(2,2,2-trifluoroethyl $\alpha$-trifluoromethacrylate), $\mathbf{P 4}$

A $100 \mathrm{~mL}$ RBF equipped with a stirbar was charged with trifluoroethyl $\alpha$-trifluoromethacrylate $(1.5 \mathrm{~mL}, 8.6 \mathrm{mmol})$, and THF $(50 \mathrm{~mL})$. This flask was chilled to $-78{ }^{\circ} \mathrm{C}$ with an acetone/dry ice bath and stirred for at least $10 \mathrm{~min}$. Separately, pyridine $(0.67 \mathrm{~mL}, 8.3 \mathrm{mmol})$ was diluted in $20 \mathrm{~mL}$ THF. This solution $(0.1 \mathrm{~mL})$ was added to the chilled monomer solution. The reaction was stirred for $3 \mathrm{~h}$ followed by precipitation of $\mathbf{P 4}$ in distilled water.

Poly(methyl methacrylate), P5

A $25 \mathrm{~mL}$ RBF with a stirbar was loaded with $\mathrm{Cu}(\mathrm{I}) \mathrm{Br}(16.9 \mathrm{mg}, 0.12 \mathrm{mmol})$ and $\mathrm{Cu}(\mathrm{II}) \mathrm{Br}(1.0 \mathrm{mg}, 0.01 \mathrm{mmol})$ in a glove box. After removing the flask from the glove box, diphenyl ether $(5 \mathrm{~mL})$ was added to the flask. Methyl methacrylate $(5 \mathrm{~mL}, 47.1 \mathrm{mmol})$ was filtered through neutral alumina and injected into the reaction vessel via syringe. N,N,N',N',N'-pentamethyldiethylenetriamine (PMDETA) $(24.6 \mu 1,0.12 \mathrm{mmol})$ was added via a micro syringe. After ethyl 2-bromoisobutyrate (E2BIB) $(14.0 \mu \mathrm{L}, 0.09 \mathrm{mmol})$ was added, the flask was immediately taken through two freeze, pump, thaw cycles and then heated to $40{ }^{\circ} \mathrm{C}$ for $8 \mathrm{~h}$. To precipitate the polymer, the reaction solution was slowly dripped into $250 \mathrm{~mL}$ of ice-cold vigorously stirring $\mathrm{MeOH}$ in an Erlenmeyer flask. The polymer was isolated using a Hirsch funnel and filter paper. The polymer was then dissolved in THF $(50 \mathrm{~mL})$ and filtered through neutral alumina to remove any residual copper. This solution was precipitated again as described above using roughly ten times the volume of $\mathrm{MeOH}$ as THF.

\subsection{Contrast Curves}

Each polymer was dissolved in PGMEA (6 wt $\%)$ and filtered $(0.22 \mu \mathrm{m}$ PTFE). P5 films were spin coated at $2000 \mathrm{rpm}$ for $60 \mathrm{sec}$ with a $90{ }^{\circ} \mathrm{C} 60 \mathrm{sec}$ Post-Application Bake (PAB). Fluoropolymers were spin coated on wafers pre-treated with AP410 at $3000 \mathrm{rpm}$ for $60 \mathrm{sec}$ with a $90{ }^{\circ} \mathrm{C} 60 \mathrm{sec}$ PAB. The resulting films were $200-400 \mathrm{~nm}$ thick. Optimized 
developers were 1:1 MIBK:IPA for PMMA, 7:3 MIBK:IPA for PMTFMA, 2:8 MIBK:IPA for PETFMA, and 6:4 MIBK:MEK for ZEP. Films were exposed to a dose array ranging from 0.1 to $100 \mu \mathrm{C} / \mathrm{cm}^{2}$, developed for $60 \mathrm{sec}$, and the film thicknesses of the resulting features were determined by profilometry and normalized to the original film thickness.

\subsection{G(s) and G(x) Determination}

A sample of polymer (40-200 mg) was dissolved in THF $(10 \mathrm{~mL})$, and five GPC chromatograms were collected by varying the overall concentration through variation of injection volumes. The $\mathrm{dn} / \mathrm{dc}$ was then determined by calculating the slope of the RI area vs concentration line. The eluent for P5 and ZEP analysis was THF while acetone was used for $\mathbf{P 1}, \mathbf{P 2}$, and P3.

A sample of each polymer ( $200 \mathrm{mg}$ ) was placed into a small glass vial. After purging with Argon for 5 min, the vial was flame sealed. The samples were irradiated with a ${ }^{60} \mathrm{Co} \gamma$ source in collaboration with the National Institute of Standards and Technology (NIST) with 2, 5, 10, and $15 \mathrm{Mrad}$ of $\gamma$-radiation. Three $1 \mathrm{wt} \%$ samples in THF were prepared for each sample and analyzed by GPC.

\section{DATA}

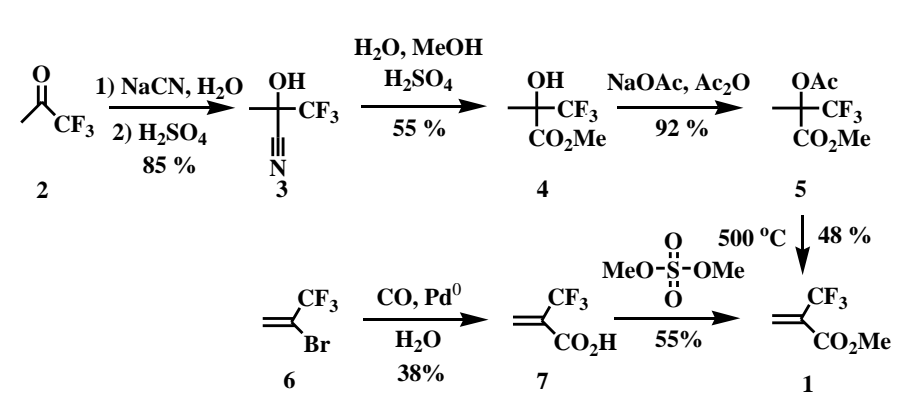

Scheme 2: Synthesis of MTFMA (5)

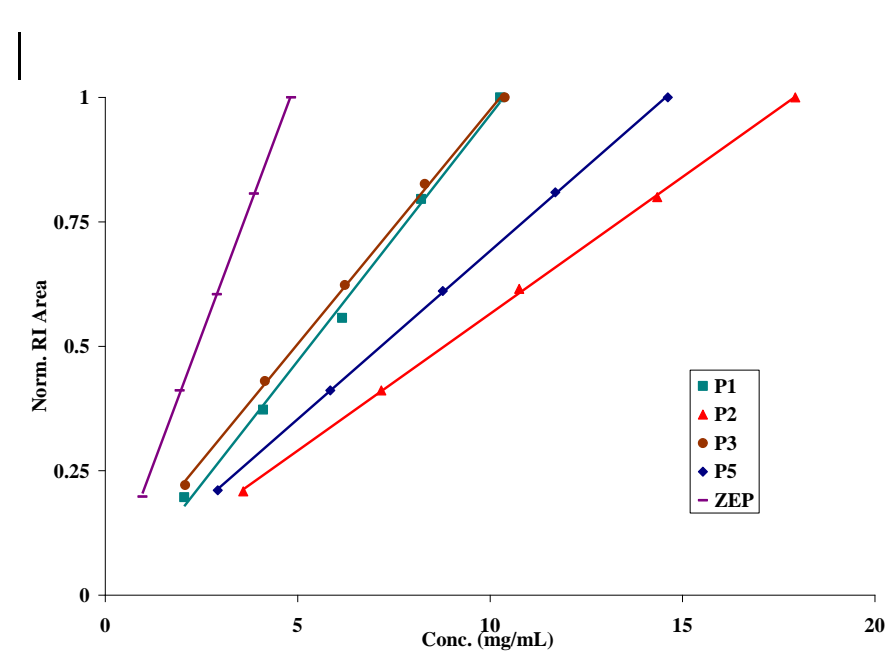

Figure 4: Normalized RI area versus concentration for calculating dn/dc of P1, P2, P3, P4, and ZEP polymers

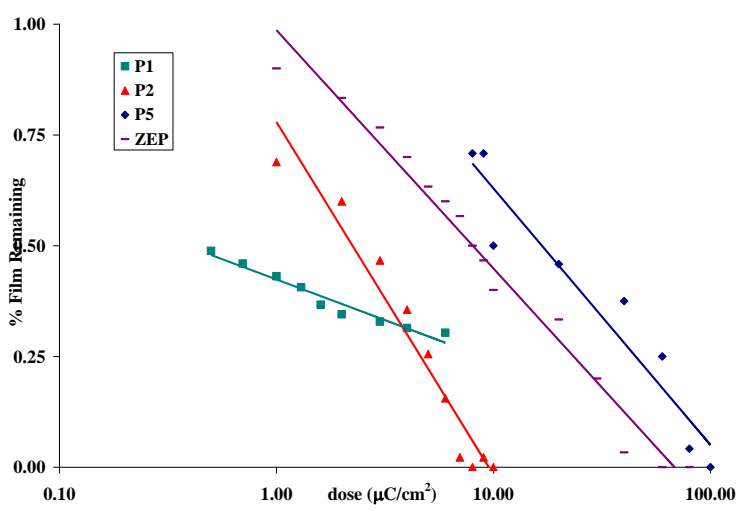

Figure 1: e-beam contrast curves for P5, ZEP, P1, and P2

Table 2: dn/dc data for P1, P2, P3, P5, and ZEP

\begin{tabular}{|c|c|c|c|c|c|}
\hline Polymer & $\mathrm{dn} / \mathrm{dc}$ & Error & $\%$ Error & $\mathrm{R}^{2}$ & Solvent \\
\hline P1 & 0.0404 & 0.0013 & $3.3 \%$ & 1.00 & Acetone \\
\hline P2 & 0.0355 & 0.0004 & $1.0 \%$ & 1.00 & Acetone \\
\hline P3 & 0.0319 & 0.0005 & $1.7 \%$ & 1.00 & Acetone \\
\hline P5 & 0.0674 & 0.0004 & $0.6 \%$ & 1.00 & THF \\
\hline ZEP & 0.1124 & 0.0011 & $1.0 \%$ & 1.00 & THF \\
\hline
\end{tabular}




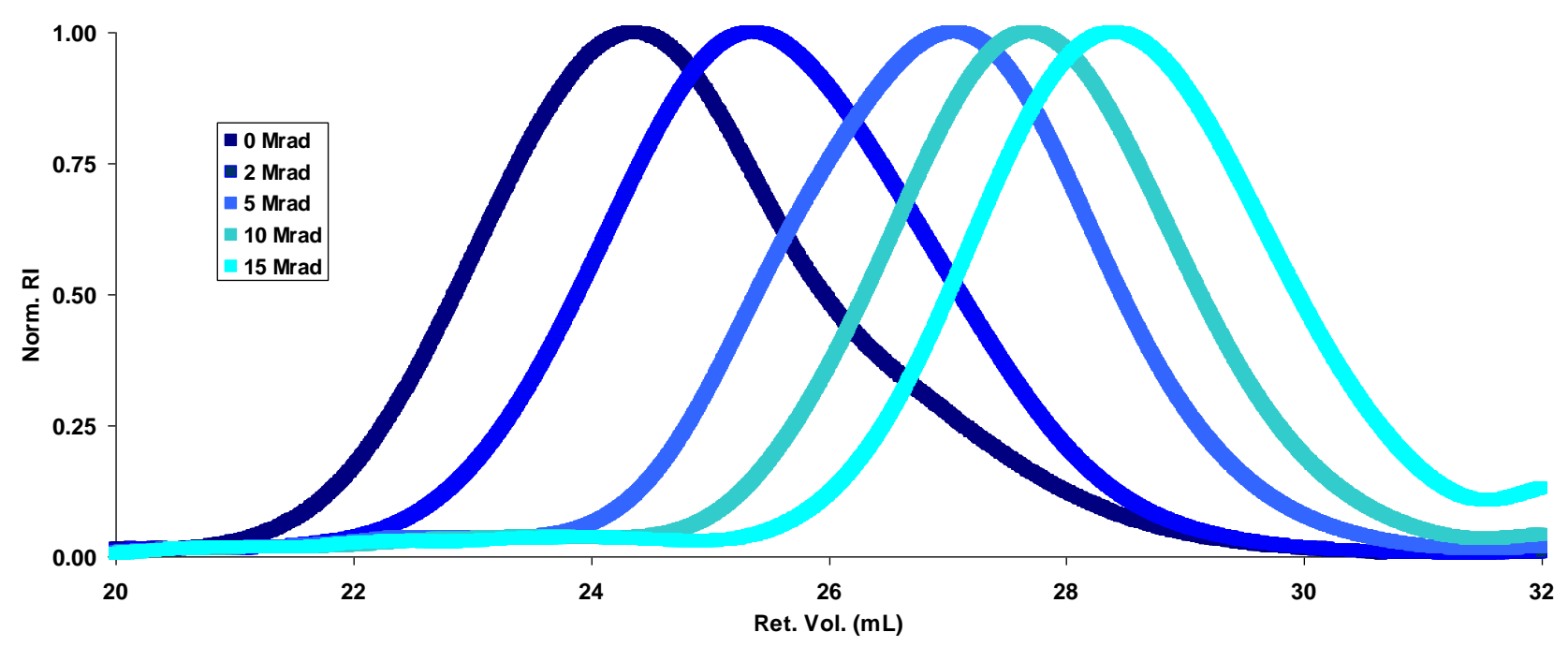

Figure 3: GPC Chromatograms of irradiated P1

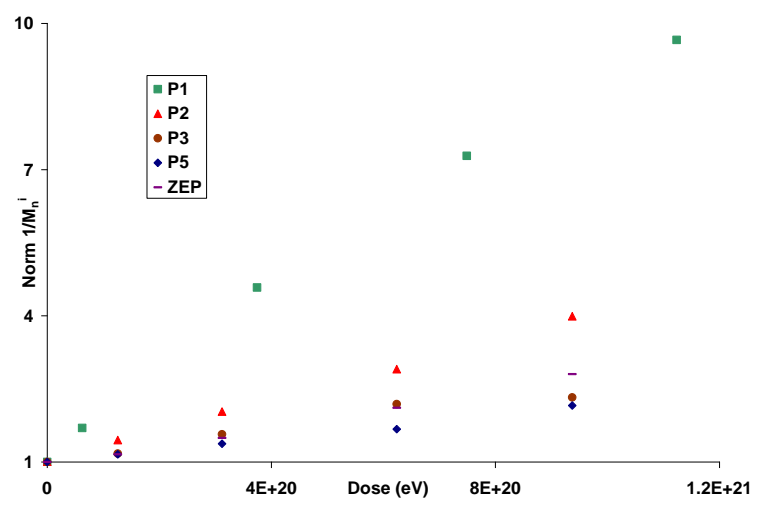

Table 2: $\mathrm{G}(\mathrm{s})$ and $\mathrm{G}(\mathrm{x})$ values for 5 polymer

\begin{tabular}{|l|c|c|c|c|c|c|}
\hline Polymer & $\mathrm{G}(\mathrm{s})$ & Error & $\mathrm{R}^{2}$ & $\mathrm{G}(\mathrm{x})$ & Error & $\mathrm{R}^{2}$ \\
\hline P1 & 3.19 & 0.15 & 0.99 & -0.02 & 0.00 & 0.98 \\
\hline P2 & 2.75 & 0.20 & 0.98 & 0.07 & 0.01 & 0.94 \\
\hline P3 & 2.80 & 0.34 & 0.95 & 0.09 & 0.01 & 0.86 \\
\hline P5 & 1.26 & 0.12 & 0.97 & -0.03 & 0.00 & 0.98 \\
\hline ZEP & 1.71 & 0.10 & 0.99 & 0.01 & 0.00 & 0.98 \\
\hline
\end{tabular}

Figure 4: Normalized $1 / \mathrm{M}_{\mathrm{n}}{ }^{\mathrm{i}}$ versus dose

\section{DISCUSSION}

\subsection{Monomer Synthesis}

The synthesis of an MMA analog with an $\alpha-\mathrm{CF}_{3}$ substituent began with the nucleophilic addition of sodium cyanide to commercially available 1,1,1-trifluoroacetone 2 under basic conditions; this yielded $\mathbf{3}$ in $60 \%$ yield, which after hydrolysis with acidic methanol gave the methyl ester $\mathbf{4}$ in $48 \%$ yield. To convert the hydroxyl group to a better leaving group, $\mathbf{4}$ was acylated to give $\mathbf{5}$ in $92 \%$ yield. Finally, $\mathbf{5}$ was converted to monomer $\mathbf{1}$ via pyrolysis in $46 \%$ yield. The key to the pyrolysis process was accurately measuring the temperature with properly placed temperature probes and carefully controlling the speed at which $\mathbf{5}$ was passed through the quartz column. This 4-step previously published process yields 1 in $12 \%$ overall yield (Scheme 2). ${ }^{12}$ Desiring a more efficient route, commercially available vinylbromide $\mathbf{6}$ was converted to acid $\mathbf{7}$ by a palladium catalyzed carbonylation in $38 \%$ yield. ${ }^{11}$ Needing to convert the acid to a methyl ester, acid 7 was subjected to several methylating conditions including Fisher esterification, diazomethane, amine bases with methyl iodide, DCC coupling, and Meerwein's salt with no detectable formation of product due to the base sensitivity of $\mathbf{1}$, but the ester was recovered in $55 \%$ yield when the acid was reacted with neat dimethyl sulfate at $120{ }^{\circ} \mathrm{C}$ for $48 \mathrm{~h}^{13}$ 


\subsection{Polymer Synthesis}

Homopolymers

Delaire noted that a resist's sensitivity is inversely proportional to it's polydispersity index. ${ }^{14}$ Acrylates without an $\alpha$ $\mathrm{CF}_{3}$ substituent are polymerizable via ATRP thus MMA and TFEMA were polymerized in this way. ${ }^{15,16} \mathbf{P 5}$ was desired for comparative purposes to understand the effect of the introduction of fluorine. P3 was envisioned as a means to determine the effect of fluorine incorporation in a position believed not to effect chain scission.

The remaining fluorinated monomers required their own unique and specific polymerization conditions as recently noted by Hamana. ${ }^{17}$ Monomer 1 was polymerized using potassium acetate and 18-crown-6 according to a procedure developed by Ito (Scheme 1). ${ }^{18}$ Narita et al. reported the anionic polymerization of ETFMA; ${ }^{19,20}$ however, these experimental conditions were not reproducible. Different initiators including potassium acetate with 18-crown- $6, n$ butyllithium, and pyridine among others were tested without success, however potassium tert-butoxide ( $\mathrm{KO} t$ - $\mathrm{Bu})$ was determined to be an effective initiator at $-78^{\circ} \mathrm{C}$.

$n$-Butyllithium and $n$-butylmagnesium chloride were reported to polymerize TFETFMA ${ }^{21}$, but reproduction of these conditions yielded no polymer. Pyridine was used as the initiator at $-78{ }^{\circ} \mathrm{C}$ in $\mathrm{THF},{ }^{22}$ but all attempts to polymerize this monomer produced an insoluble material with a high affinity for Teflon ${ }^{\circledR}$ stir bars. Due to the material's intractable nature, no characterization data is available.

Copolymers

Replacement of methyl $\alpha$-chloroacrylate monomer in ZEP with $\mathbf{1}$ was initially targeted; unfortunately, attempts to polymerize $\mathbf{1}$ and $\alpha$-methyl styrene via traditional radical polymerization conditions failed. Copolymerizations of $\mathbf{1}$ and various ratios of styrene produced materials with less than $5 \%$ incorporation of $\mathbf{1}$ as determined by ${ }^{1} \mathrm{H}-\mathrm{NMR}$. Due to this difficulty and given that current acrylate-based $193 \mathrm{~nm}$ resists display adequate etch resistance, incorporation of a more etch resistant monomer was determined not to be a fundamental necessity to compare resist performance.

To further investigate it's unusual reactivity, $\mathbf{1}$ was radically copolymerized with MMA. As has been noted elsewhere a maximum 50\% incorporation of $\mathbf{1}$ was obtained in copolymers regardless of feed ratios. ${ }^{9} \mathbf{1}$ was also radically copolymerized with TFEMA. The resulting materials were less soluble in THF and common casting solvents possibly due to the $-\mathrm{CH}_{2} \mathrm{CF}_{3}$ alkoxy functionality.

\subsection{Contrast Curves}

Resist sensitivity was investigated by subjecting a film of each polymer to varying doses of e-beam radiation then developing the wafer. The depth of the features was measured using profilometry and compared to the original film thickness. As shown in Figure 1, the contrast for P5 and ZEP are very similar, however P1 and P2 are much more sensitive requiring nearly two orders of magnitude less dose to develop. ${ }^{5}$ Although the contrast for P1 for the investigated conditions is poor, subsequent work was able to demonstrate good contrast. P2 displays higher contrast than P5 and ZEP.

\subsection{G(s) and G(x) Determination}

Polymer Characterization

As noted by Romack et al. fluorinated polymers have unique properties including low Refractive Indices (RIs) that make molecular weight determination by a lone RI detector prone to error. ${ }^{23,24}$ While fluorinated solvents can increase the solubility of the polymer and improve the signal-to-noise ratio of an RI detector, these solvents are expensive and environmentally unfriendly. ${ }^{25}$ To accurately determine the molecular weights of these polymers, a triple detection method that utilizes an RI detector, right-angle light scattering, and low-angle light scattering $\left(\lambda_{0}=670 \mathrm{~nm}\right)$ detectors, and a four-capillary differential viscometer was employed.

It was determined that acetone was an appropriate solvent for P1, P2, and P3 while THF was used for P5 and ZEP. ${ }^{26}$ Through serial dilutions the $\mathrm{dn} / \mathrm{dc}$ of each polymer was determined (Figure 2), and Table 1 lists these values including error analysis and correlation coefficients. The $\mathrm{dn} / \mathrm{dc}$ calculated for $\mathbf{P 5}$ is in good agreement with literature, and all data show an extremely high linear correlation. ${ }^{27}$ 
While contrast curves are a necessary experiment to test a resist's viability, the experiment contains several variables including solution concentration, spin speed, PAB bake time and temperature and, perhaps most importantly, developer that all play a role in a resist's contrast. To determine an absolute value of these resists' sensitivity to radiation, the Gvalues were determined. A polymer's sensitivity to backbone scission may be quantified by bombarding a sample with $\gamma$-radiation from a ${ }^{60}$ Co source then measuring the change of the $M_{n}$ and $M_{w}$ of the sample. ${ }^{6}$ Equations 1 and 2 display the linear relationships between a material's change in $M_{n}$ and $M_{w}$ as a function of dose and it's $G(s)$ and $G(x)$ values. $\mathrm{G}(\mathrm{s})$ represents the number of backbone scissions per 100 electron-volts $(\mathrm{eV})$ absorbed while $\mathrm{G}(\mathrm{x})$ is the cross-linking efficiency per $100 \mathrm{eV}$ absorbed. A polymer's sensitivity to this method has been shown to correlate well to e-beam sensitivity.

$$
\begin{gathered}
\frac{1}{M_{n}{ }^{o}}=\frac{G(s)-G(x)}{100 * N_{A}}(\text { dose })+\frac{1}{M_{n}{ }^{i}} \\
\frac{1}{M_{w}{ }^{o}}=\frac{G(s)-4 * G(x)}{200 * N_{A}}(\text { dose })+\frac{1}{M_{w}{ }^{i}}
\end{gathered}
$$

Samples of P1, P2, P3, P5, and ZEP were sealed in glass vials under Argon and exposed at NIST to varying doses of

${ }^{60} \mathrm{Co} \gamma$-radiation. Utilizing the previously described GPC detection system, the $\mathrm{M}_{\mathrm{n}}$ and $\mathrm{M}_{\mathrm{w}}$ of the initial and irradiated polymer samples were determined. These values were analyzed using the following relations where the dose is expressed in units of $e V, N_{A}$ is Avagadro's number, $M_{n}{ }^{\circ}$ and $M_{n}{ }^{i}$ are the number-average molecular weights of the irradiated and initial polymer samples, respectively, and $\mathrm{M}_{\mathrm{w}}{ }^{\circ}$ and $\mathrm{M}_{\mathrm{w}}{ }^{\mathrm{i}}$ are the weight-average molecular weights of the irradiated and initial polymer samples, respectively.

Figure 3 is representative data from GPC chromatograms of irradiated P1. As dose increased, the retention volume increased indicating a decrease in molecular weight. By substituting the experimental values into equations 1 and 2 , the $\mathrm{G}(\mathrm{s})$ and $\mathrm{G}(\mathrm{x})$ values for each of the polymers were determined (Figure 4); Table 2 displays the polymers' $\mathrm{G}(\mathrm{s})$ and $\mathrm{G}(\mathrm{x})$ values with error analysis. The experimentally determined $\mathrm{G}(\mathrm{s})$ and $\mathrm{G}(\mathrm{x})$ values for $\mathbf{P 5}(1.26,0.12)$ are in good agreement with literature values $(1.3,0.0),{ }^{6}$ however, the $\mathrm{G}(\mathrm{s})$ value for P1 (3.19) is higher than previously reported (2.5), ${ }^{9}$ which could be attributed to a more accurate determination of $M_{n}$ and $M_{w}$. Overall, the $G(s)$ values for the fluorinated polymers are higher than that of both P5 (1.26) and ZEP (1.71). None of the fluorinated polymers have a significant $\mathrm{G}(\mathrm{x})$ component, as expected by eliminating the dissociative-electron capture mechanism. A surprising find was the similarity of the G(s) values for $\mathbf{P 2}$ (2.75) and $\mathbf{P 3}$ (2.80). It was hypothesized that $\mathbf{P 3}$ would have a lower scission efficiency than $\mathbf{P 2}$ due to the lack of an $\alpha-\mathrm{CF}_{3}$ substituent; The effect of the $-\mathrm{CH}_{2} \mathrm{CF}_{3}$ alkoxy substituent on the $\mathrm{G}(\mathrm{s})$ warrants further study. Given that poly(methyl $\alpha$-chloroacrylate) has a $\mathrm{G}(\mathrm{x})$ value of $0.8^{28}$, it was expected that ZEP, which has $50 \mathrm{~mol} \%$ methyl $\alpha$-chloroacrylate, would exhibit a significant cross-linking component. It is notable the $\mathrm{G}(\mathrm{x})$ value for ZEP (0.01) is negligible, indicating the effect of the $\alpha$-methyl styrene must be significant.

\subsection{EUV}

It has been noted as fluorine content of MMA increases, the optical density of the resulting polymeric resist to EUV irradiation $(13.4 \mathrm{~nm})$ increases significantly. This allows for a thinner optimal film thickness, which will be necessary for the production of $22 \mathrm{~nm}$ and smaller features. ${ }^{10}$

To compare the photospeed of $\mathbf{P 5}$ and $\mathbf{P 1}$, films of nearly identical thickness were spin coated and exposed to varying doses of e-beam and EUV irradiation. These films were then developed in the same developer. This was a challenge as the vastly different solubility characteristics of these materials made it diffucult to find an effective developer for both systems. Scanning electron microscopy images were collected, and the e-beam photospeed of $\mathbf{P 1}$ was determined to be 2.8x faster than that of P5. The EUV photospeed of P1 compared to P5 was found to be 4.0x, of which 1.5x can be attributed to the increase in EUV absorbance. ${ }^{10}$ 


\section{CONCLUSION}

A variety of fluorinated polyacrylates have been shown to be more sensitive than P5 and ZEP to e-beam, $\gamma{ }^{60} \mathrm{Co}$, and EUV irradiation. This was demonstrated quantitatively in e-beam contrast curves that showed $\mathbf{P 1}$ and $\mathbf{P 2}$ required nearly a 100x less dose to develop than P5 and 10x less dose than ZEP. The G(s) value for P1, P2, and P3 was higher than P5 and ZEP, confirming the e-beam sensitivity results. In addition, no polymer had a significant $\mathrm{G}(\mathrm{x})$ value, meaning there was no measurable cross-linking upon ${ }^{60} \mathrm{Co} \gamma$-irradiation. Finally, the EUV photospeed of P1 compared to P5 was found to be 4.0x, of which $1.5 \mathrm{x}$ can be attributed to the increase in EUV absorbance due to the incorporation of fluorine. These materials, including copolymers with more fluorine content, will continue to be investigated for their applicability as both e-beam and EUV non-chemically amplified resists.

\section{ACKNOWLEDGMENTS}

The authors would like to thank Central Glass Co. for their donations of fluorinated monomers, Dr. Peter Carmichael of NIST for his help with the ${ }^{60} \mathrm{Co}$ irradiations, Mike Ronalter of UT for his help with sample preparations, and Brent Norris of UT, David Kiddy of Agilent, and Michael Murphy of Viscotek for their help with the GPC analysis. We would also like to thank Prof. Bruce Smith of RIT for his simulation data, and NSF R05-0126, Applied Materials, and the Texas Advanced Materials Research Center for their generous support of this research.

\section{REFERENCES}

1 LaPedus, Mark. "Analysis: Photomask business model is broken." EE Times 10 Oct. 2008: 1-5.

2 "International Technology Roadmap for Semiconductors." 2007. <http://www.itrs.net/reports.html>.

3 Slot, E.; Wieland, M. J.; de Boer, G.; Kruit, P.; ten Berge, G. F.; Houkes, A. M. C.; Jager, R.; van de Peut, T.; Peijster, J. J. M.; Steenbrink, S. W. H. K.; Teepen, T. F.; van Veen, A. H. V.; Kampherbeek, B. J.; "MAPPER: high throughput maskless lithography," Proceedings of SPIE, 6921(Pt. 1, Emerging Lithographic Technologies XII), 69211P/1-69211P/9 (2008).

4 Hwang, S.; Kim, H.; Yeo, J.; Eynon, B.; "Full-Field Imprinting of Sub-40nm Patterns," SPIE, Adv. Litho. Conf., Feb 2008.

5 Medeiros, D. R.; Aviram, A.; Guarnieri, T. C.; Huang, W.; Kwong, R.; Magg, C. K.; Mahorowala, A. P.; Moreau, W. M.; Petrillo, K. E.; Angelopoulos, M., "Recent progress in electron-beam resists for advanced mask-making," IBM Journal of Research and Development, 45(5), 639-650 (2001).

6 Thompson, L F.; Willson, C. G.; Bowden, M. J., [Introduction to Microlithography]. 2nd ed. Washington D.C.: American Chemical Society, 1983.

7 Nishida, T.; Notomi, M.; Iga, R., "Quantum wire fabrication by electron-beam lithography using high-resolution and high-sensitivity electron-beam resist ZEP-520,” Jpn. J. Appl. Phys., 31(12B), 4508-4514 (1992).

8 Helbert, J. N.; Chen, C.; Pittman, C. U.; Hagnauer, G. L., "Radiation degradation study of poly(methyl $\square$ chloroacrylate) and the methyl methacrylate copolymer," Macromolecules, 11(6), 1104-1109 (1978).

9 Willson, C. G.; Ito, H.; Miller, D. C.; Tessier, T. G., "Poly(methyl $\alpha$-trifluoromethylacrylate) as a positive electron beam resist," Polym. Eng. Sci., 23(18), 1000-1003 (1983).

10 Gronhied, R.; Fonesca, C.; Leeson, M. J.; Adams, J. R.; Strahan, J. R.; Willson, C. G.; Smith, B. W.; "EUV Resist Requirements: Absorbance and Acid Yield," J. Micro/Nanolithogr. MEMS MOEMS, 2009 (Submitted).

11 Fuchikami, T.; Yamanouchi, A.; Ojima, I. "An effective and convenient route to 5-(trifluoromethyl)-5,6dihydrouracils and their thio derivatives." Synthesis, 9, 766-8 (1984).

12 Trinque, Brian C. Synthesis, copolymerization studies and $157 \mathrm{~nm}$ photolithography applications of 2trifluoromethacrylates. Diss. The University of Texas at Austin, 2003. Austin, TX.

13 Khramov, Dimitri M. Novel N-Heterocyclic Carbenes: Applications in Materials Chemistry and Catalysis. Diss. The University of Texas at Austin, 2008. Austin, TX.

14 Delaire, J. A.; Lagarde, M.; Broussoux, D.; Dubois, J. C., "Effects of molecular weights and polydispersity on the properties of poly(trifluoroethyl methacrylate) as a positive x-ray and electron resist," J. Vac. Sci. Technol. B, 8(1), 33-38 (1990). 
15 Wang, J.; Grimaud, T.; Matyjaszewski, K., "Kinetic Study of the Homogeneous Atom Transfer Radical Polymerization of Methyl Methacrylate," Macromolecules, 30(21), 6507-6512 (1997).

16 Matyjaszewski, K.; Wang, J.; Grimaud, T.; Shipp, D. A., "Controlled/"living" atom transfer radical polymerization of methyl methacrylate using various initiation systems," Macromolecules, 31(5), 1527-1534 (1998).

17 Umino, Y.; Narita, T.; Hamana, H., "Initiation reactivity of anionic polymerization of fluorinated acrylates and methacrylates with diethyl(ethyl cyanoacetato)aluminum," J. Polym. Sci., Part A: Polym. Chem., 46(21), 7011-7021 (2008).

18 Ito, H.; Schwalm, R., “Anionic polymerization of $\alpha$-(trifluoromethyl)acrylate,” Rec. Adv. Anion. Poly., 421-430 (1987).

19 Narita, T.; Hagiwara, T.; Hamana, H.; Nara, T., "Anionic polymerization of ethyl 2-trifluoromethylacrylate with organoaluminum and ate complex initiators," Polymer Journal, 20(3), 277-279 (1988).

20 Narita, T.; Hagiwara, T.; Hamana, H.; Nara, T., "Anionic polymerization of ethyl 2-(trifluoromethyl)acrylate," Makromol. Chem., Rapid Commun., 6(5), 301-304 (1985).

21 Narita, T.; Hagiwara, T.; Hamana, H.; Maesaka, S., "Anionic polymerization of fluoroalkyl 2trifluoromethylacrylate," Polymer Journal, 20(6), 519-523 (1988).

22 Personal correspondence with Satoshi Kikichi and Yusuke Saito of Central Glass Co.

23 Romack, T. J.; Harrison, Z. J.; French, D. V.; Amin, D. H.; Hartsell, J. L.; Meyer, J. D., "GPC-MALS Characterization of Fluoropolymers in a $\alpha, \alpha, \alpha$-Trifluorotoluene Mobile Phase: An Enabling Step in the Syntheses of Well-Defined Fluoropolymer-Based Self-Assembling Materials," Macromolecules, 40(20), 7180-7183 (2007).

24 Netopilik, M.; Kratochvil, P., "Polystyrene-equivalent molecular weight versus true molecular weight in sizeexclusion chromatography," Polymer, 44(12), 3431-3436 (2003).

25 Isemura T.; Kakita R.; Kawahara, K., "Dichloropentafluoropropanes as solvents for size exclusion chromatography,” J. Chromatogr. A, 1026(1-2), 109-116 (2004).

26 Personal Correspondence with the R\&D division of Viscotek Corp.

27 Brandrup, J. [Polymer Handbook] Ed. Edmund H. Immergut and E. A. Grulk. 4th ed., Wiley-Interscience, New York, VII/432 (1999).

28 Chen, C.; Pittman, C., "Radiation Degradation of Methyl $\alpha$-chloroacrylate-Methacrylonitrile Copolymers," J. Poly Sci. 18, 169-178 (1980). 